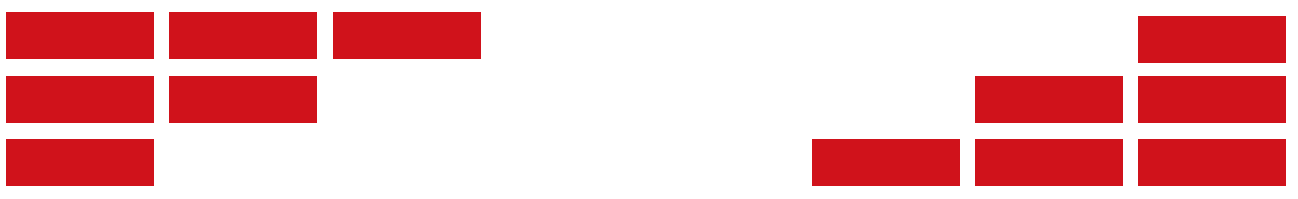

\title{
Costo económico de la impunidad
}

\section{Economic Cost of Impunity}

Eva Olimpia Arceo Gómez Universidad Iberoamericana Ciudad de México eva.arceo@ibero.mx

Este artículo recibió financiamiento de ITESo y Creatura para su elaboración. Agradezco los comentarios de Alejandro Anaya, Patricia de Obeso y dos dictaminadores anónimos que hicieron que este artículo mejorara enormemente de sus versiones iniciales. Igualmente agradezco muchísimo a Alejandra Villegas Gutiérrez por su ayuda en la edición y revisión de este artículo. Todos los errores restantes son exclusivamente míos. 


\section{Resumen}

El objetivo de este documento es hacer una estimación educada del costo económico de la impunidad en México, específicamente, aquella relacionada con homicidios, desapariciones y desplazamientos forzados durante la guerra contra el narco. La estimación fue realizada en tres etapas. Primero, se llevó a cabo una amplia revisión de la literatura sobre los costos de la violencia criminal relacionada con la guerra contra el narco, y la relación entre calidad institucional, impunidad y legitimidad de las instituciones en homicidios. En una segunda etapa, se estimaron los costos económicos de las pérdidas de vidas mediante una imputación del flujo salarial no realizado de las víctimas. Finalmente, se estimó el costo económico de la impunidad en México con base en las etapas anteriores. Los resultados muestran que para 2030, si no se perpetra ni un asesinato más, se habrán perdido $\$ 1.8$ billones de pesos en comparación con una senda de crecimiento sin asesinatos ni desaparecidos, mientras que para 2050 el costo ascendería a $\$ 8.7$ billones de pesos.

Palabras clave: crimen, crecimiento económico, narcotráfico, México.

\section{Abstract}

The objective of this document is to make an educated estimation of the economic cost of impunity in Mexico, specifically, of the costs related to homicides, disappearances and forced displacement during the War on Narco. The analysis was carried out in three stages. First, a comprehensive review of the literature was conducted on the costs of criminal violence since the war against drugs began in Mexico, as well as on the relationship between institutional quality, impunity, and legitimacy of institutions in homicides. In a second stage, the economic costs of the loss of lives were estimated by imputing the unrealized salary flow of the victims. Finally, based on the previous stages, the economic cost of impunity in Mexico was estimated. The results show that by 2030 , if not one more murder is perpetrated, we will lose $\$ 1.8$ billion pesos compared to a growth path where there are no murders or missing persons. By 2050, the cost would amount up to $\$ 8.7$ billion pesos.

Keywords: crime, economic growth, drug trafficking, Mexico.

JEL codes: O10, O54, K42

Fecha de recepción: 14 de septiembre de 2021.

Fecha de aceptación: 16 de noviembre de 2021.

Fecha de publicación: 17 de enero de 2022. 


\section{Introducción}

En México el crimen no pasa desapercibido por la población, pero al parecer sí por el aparato de justicia. De acuerdo con los datos de la Encuesta Nacional de Victimización y Percepción sobre Seguridad Pública (ENVIPE) 2018, más del 93\% de los crímenes ni siquiera son denunciados a las autoridades correspondientes. Esta cifra negra no es sino uno de los síntomas de la impunidad en México: la población no cree que el sistema de justicia funcione y, en ocasiones, teme que el mismo sistema esté en connivencia con el crimen organizado. Por ejemplo, los datos de la ENVIPE 2018 también muestran que, del total de averiguaciones previas iniciadas, en casi $56 \%$ de los casos no se resuelve la denuncia. Por tanto, más de 96\% de los crímenes no tienen una consecuencia, ya sea por la falta de denuncia o de resolución por parte del sistema judicial. El Instituto Nacional de Estadística y Geografía (INEGI, 2018) reporta que el costo económico del crimen, en 2017, fue de $1.65 \%$ del Producto Interno Bruto (РІВ), y este incluye las pérdidas materiales asociadas a él, así como el costo de medidas preventivas en su contra. Sin embargo, el costo del crimen va más allá de esta estimación, la cual no considera las pérdidas humanas (vidas, desapariciones y desplazamientos forzados), ni los cambios en el comportamiento de los individuos asociados a la percepción del crimen. Además, a la fecha no existe un estimado del costo económico de la impunidad prevaleciente en México. En este artículo, se hará una revisión extensiva de la literatura sobre los costos económicos del crimen, y sobre la relación entre este y la impunidad, la cual se entiende como la falta de responsabilidad penal ante la comisión de un delito. A partir de este trabajo previo se obtendrá una estimación del costo del crimen y de la impunidad más general.

En economía, Becker (1968) teorizó sobre la decisión individual de dedicarse a actividades criminales. De acuerdo con esta teoría, a mayor impunidad esperaríamos observar un aumento en la actividad criminal, donde la impunidad se entiende como la falta de responsabilidad penal tras la comisión de un delito. El modelo no especifica el tipo de actividad criminal, pero es aplicable a cualquier clase de ofensa, desde el robo hasta violaciones a los derechos humanos. Aunque no se habla de impunidad explícitamente, Becker modela las actividades o el esfuerzo por parte del sistema judicial para castigar al delito, así como la decisión de los individuos de incurrir en algún crimen. Las dos variables más importantes que se consideran en la acción pública son la probabilidad de que cada tipo de ofensa resulte en una condena y la severidad de la pena por cada una. Tanto 
la probabilidad de dictar una pena como su severidad están directamente relacionadas con el costo del crimen: a menor probabilidad o severidad de la sentencia, menor costo de involucrarse en actividades criminales.

Por su parte, como veremos en la revisión de literatura, existen muchos mecanismos que median la relación entre el crimen y una caída en la actividad económica. Primero, está la falta de incentivos a la inversión privada en capital físico que podría ser incautado o afectado por el crimen organizado. Segundo, está la falta de incentivos a la inversión en capital humano debido a disminuciones en la esperanza de vida de los jóvenes y a aumentos en los incentivos para participar en actividades delictivas que no requieren mayor formación educativa. Tercero, las experiencias directas de violencia criminal, así como las percepciones de inseguridad generan un ambiente estresante, el cual deteriora la salud de la población que, a su vez, repercute en su productividad. Cuarto, está el incremento en actividades de riesgo por parte de la juventud que observa un ambiente criminal (altamente riesgoso) como una normalidad en sus condiciones de vida. Estas actividades de riesgo podrían conducir a mayor consumo de alcohol y drogas, mayor actividad delictiva y mayores tasas de embarazo adolescente. Quinto, además de una disminución en inversión en capital humano (un flujo) debido a la reducción en años de escolaridad completados y peor salud, está una caída en el stock de capital humano dados los homicidios, las desapariciones y los desplazamientos forzados en distintas regiones. Así, el crimen provoca una caída generalizada del bienestar más allá del PIB per cápita. En este documento exploraremos únicamente el primer mecanismo y el quinto ${ }^{1}$ para estimar el costo económico de la violencia criminal mediante una estimación del valor presente de los salarios promedio no devengados por los asesinados, así como el efecto directo sobre el capital físico de la economía y las estimaciones sobre el crecimiento económico que se hallan en la literatura.

Una vez determinado el costo económico de la creciente violencia en el país, abordaremos la relación que existe entre la calidad de las instituciones de justicia o la impunidad en los homicidios, las desapariciones y los desplazamientos forzados. Esto nos permitirá hacer un estimado de qué tanto se podrían reducir estos crímenes y desplazamientos si lográramos reducir la impunidad. Uno de los escenarios que consideramos es, por ejemplo, aumentar la calidad institucional

1 El Apéndice en línea presenta la revisión de literatura de los otros tres mecanismos identificados. No se consideran en la estimación debido a la dificultad de establecer contrafactuales realistas. 
o reducir la impunidad al nivel de Costa Rica. A partir de la medición de esta relación y la del costo económico de la violencia criminal estimaremos el costo económico de la impunidad en México.

Una limitante del análisis es que el costo estimado se refiere solo a aquellas actividades o consecuencias que se pueden monetizar. Por ejemplo, no podemos decir nada sobre el costo psíquico en los familiares de los desaparecidos y los asesinados. Además, nuestro análisis no considera los costos de todo tipo de crímenes, sino que se enfoca únicamente en desapariciones y homicidios. Tampoco contamos con una estimación total de los gastos que sí son monetarios, como aquellos en que incurren las familias para buscar a sus seres queridos, los funerarios de los asesinados, abogados, traslados y pagos burocráticos destinados a buscar justicia. Además, hacemos caso omiso del costo de los niños y las niñas que no nacieron por la muerte de la población en edad reproductiva. Finalmente, no podemos evitar hacer una doble contabilidad de algunos de los costos. Por ejemplo, parte del costo en el PIB que estima la literatura se puede deber a disminuciones en la población dados los homicidios, las desaparecidos y los desplazados. Sin embargo, difícilmente aquello que no logramos contabilizar es menor a lo que contabilizamos por partida doble. Así, lo que presentamos como el costo económico de la impunidad es muy probablemente una subestimación del costo real de la impunidad. Aun así, nuestras cifras indican que la impunidad es muy onerosa.

Organizamos el resto del documento de la siguiente manera. En la sección 2 presentamos la revisión de la literatura sobre la cual basaremos el estimado del costo económico de la violencia criminal; en la 3 abordamos la estimación del costo de la violencia criminal, y finalmente, en la sección 4 concluimos.

\section{Revisión de literatura}

\subsection{Efectos de la violencia criminal en homicidios, desplazados y desaparecidos}

El efecto más directo de la violencia criminal, y posiblemente uno de los más dolorosos para la sociedad mexicana, ha sido la pérdida de vidas humanas y las desapariciones. Desde que Felipe Calderón declaró la guerra contra el narco a fines de 2006, se han contabilizado casi 229 mil homicidios dolosos en México. ${ }^{2}$

2 El resto de la revisión de literatura se referirá únicamente a homicidios, aunque se refiere a homicidios dolosos. En la sección 3 detallamos el tipo de homicidios incluidos en la estimación del costo. 
La Gráfica 1, Panel A, muestra la evolución del número de estos de 1997 a 2018, que en el país aumentó aproximadamente de 10 mil en 2007 a 22500 en 2011. A partir de 2011 se observa una disminución, pero para 2018 ya se habían rebasado los 28 mil homicidios al ańo. El Panel B muestra que la tasa sigue la misma trayectoria y subió de 9.4 homicidios por cada 100 mil habitantes a 23 por cada 100 mil habitantes en 2018.

\section{Gráfica 1. Evolución de los homicidios en México: 1997-2018}

A. NÚMERO DE HOMICIDIOS

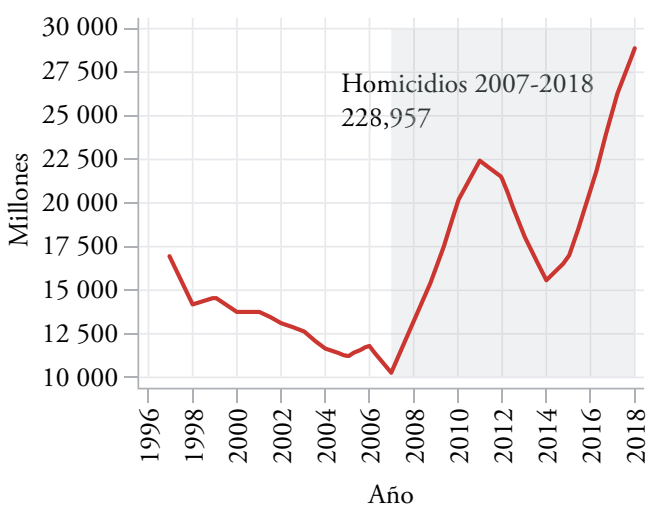

B. TASA DE HOMICIDIOS POR CADA 100 MIL HABITANTES

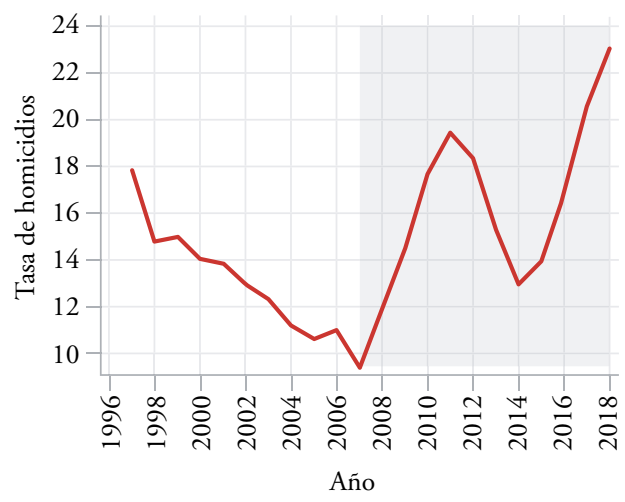

Fuente: Elaboración propia con base en datos del Secretariado Ejecutivo del Sistema Nacional de Seguridad Pública. El área sombreada corresponde al período posterior al inicio de la guerra contra el narco.

Si bien para efectos de este documento la medida relevante ideal sería el costo del total de crímenes, la mayor parte de los trabajos consultados explotan el aumento dramático en los homicidios a partir de 2007-2008. La literatura ha identificado varios mecanismos detrás del incremento en los homicidios en México. El más recurrente es la guerra contra el narco. Escalante (2011) documenta que los estados con operativos conjuntos de fuerzas federales militares y policíacas observan un mayor aumento en la tasa de homicidios. Merino (2011) formaliza un poco más este resultado mediante pareamiento en la probabilidad de tener 
un operativo conjunto, ${ }^{3}$ y también encuentra que los estados que lo llevan a cabo observan un incremento en los homicidios de alrededor de 52\%. Calderón et al. (2015) usan una estrategia de diferencia-en-diferencias ${ }^{4}$ para estimar el efecto de la decapitación de los cárteles de las drogas en los homicidios, y encuentran también que estos se incrementaron en alrededor de $52 \%$. Por su parte, mediante una regresión discontinua en los resultados de elecciones cerradas donde ganó el Partido Acción Nacional (PAN), Dell (2015) estima que tener un presidente municipal panista (y la consecuente cooperación con el gobierno de Felipe Calderón) aumentaron los homicidios en 53\%. Finalmente, mediante un modelo de efectos fijos y un estimador de Arellano-Bond, Balmori de la Miyar (2016) indica que tanto los operativos conjuntos como la intensidad del patrullaje (medida por el número de incautaciones de drogas y detenciones de personas por cada 100 mil habitantes) explican hasta el 30.8\% de la variación en las tasas de homicidios relacionadas con el narco.

Además de la guerra contra el narco se han investigado otros tres canales, los cuales, en su conjunto, hubiesen predicho un aumento en la violencia criminal aun sin la declaración de guerra. Primero, Castillo et al. (2018) encuentran que las incautaciones de cocaína en Colombia están relacionadas con el aumento de homicidios vinculados al narco. Estas incautaciones provocan que haya una menor oferta de cocaína en los mercados y, por tanto, que aumente su precio. Esto conlleva, a su vez, a una mayor renta del tráfico de cocaína e intensifica la lucha por el control de las rutas en México. Las incautaciones de cocaína en Colombia explican alrededor de 17\% de los homicidios relacionados con el narco en México. Segundo, Dube et al. (2013) encuentran que el vencimiento de la Prohibición Federal de Armas de Asalto de Estados Unidos, ${ }^{5}$ en 2004, facilitó el tráfico de este tipo de armamento hacia México. Ellos señalan que el vencimiento de esta re-

3 Este pareamiento pretende hacer comparaciones entre estados que son comparables debido a que los operativos conjuntos se realizaron en entidades con ciertas características. Si estas características determinan también el nivel de asesinatos antes de la introducción de operativos, entonces se atribuirían a los operativos asesinatos que no les corresponden.

4 Las estimaciones por diferencia-en-diferencias comparan el antes y el después de los estados donde aumentó mucho la violencia criminal con aquellos donde aumentó poco (o nada).

5 Esta prohibición estaba destinada a regular la producción de armas semiautomáticas y cartuchos de municiones de gran capacidad para el uso de la población civil. Entró en vigor en 1994 y duró 10 años. 
gulación provocó, cuando menos, un aumento de $16 \%$ en la tasa de homicidios en México. Finalmente, Dube et al. (2016) encuentran que las variaciones internacionales en el precio del maíz inducen a más agricultores a plantar marihuana y amapola, y en consecuencia afectan la tasa de homicidios. Ellos estiman que el aumento de $8 \%$ en los precios del maíz entre 2007 y 2008 condujo a $11 \%$ menos de homicidios en los municipios apropiados para cultivar maíz, en comparación con los no apropiados para esta actividad.

La tasa de homicidios se ha incrementado de tal forma que la esperanza de vida de los hombres se ha mantenido estable en 72 años, algo que no se observaba con tanta claridad desde hace décadas. En contraste, la esperanza de vida de las mujeres se ha incrementado en 0.6 ańos entre 2000 y 2010, de 77.2 a 77.8 años (Canudas-Romo et al., 2015). Suponiendo que los hombres hubieran tenido un logro similar en la esperanza de vida que las mujeres, este estancamiento representó una pérdida de 0.5 años en la esperanza de vida de los hombres, y se debe a los jóvenes, cuya esperanza de vida a los 20 años se mantuvo en 54.4 años entre 2005 y 2014; mientras que la de las mujeres a esa misma edad aumentó de 59.2 años a 59.5 años en el mismo período (Canudas-Romo et al., 2017). Además, la proporción de esta esperanza de vida que se vivirá en vulnerabilidad aumentó $39 \%$ y $40 \%$ para hombres y mujeres, respectivamente.

Esta diferencia por grupo de edad se debe al perfil de las personas asesinadas durante la guerra contra el narco. Merino et al. (2013) documentan las características de los asesinados entre 2005 y 2011. De los casi $100 \mathrm{mil}, 90 \%$ son hombres. Entre ellos, 65\% tiene entre 18 y 40 ańos (Tabla 1). Además, entre los hombres, aquellos que no concluyeron la educación media superior son quienes tienen mayor probabilidad de aparecer en las estadísticas de asesinatos. La heterogeneidad por grupo de edad y nivel educativo es tan grande que la tasa de homicidios de hombres entre 18 y 25 ańos con menos de primaria completa superaba los 300 asesinatos por cada 100 mil personas de este grupo demográfico. 
Tabla 1. Perfil de los asesinados entre 2005 y 2011 por género y edad

Total de asesinatos: 98067

$$
\text { Hombres (\%) Mujeres (\%) }
$$

A. Grupo de edad

Menores de 12 ańos

12-17 años

$981 \quad 56 \% \quad 779 \quad 44 \%$

18-25 años

3804

$80 \%$

$925 \quad 20 \%$

26-40 años

19801

$90 \%$

$2152 \quad 10 \%$

Más de 40 años

37517

$92 \%$

3259

$8 \%$

Total

25511

$88 \%$

$3338 \quad 12 \%$

87614

$89 \% \quad 10453$

$11 \%$

B. Nivel educativo

Menos de primaria

17411

Primaria completa

24892

Secundaria completa

21812

Preparatoria completa

12217

Universidad o superior

6497

Fuente: Elaboración propia con base en datos de Merino et al. (2013), Sistema Nacional de Información en Salud (Sinais).

Otro costo humano de la guerra contra el narco ha sido el de los desaparecidos. En noviembre de 2018, el Wall Street Journal reportaba 37400 desaparecidos. $^{6}$ En junio de ese mismo año, La Jornada describió su perfil: en su mayoría hombres entre 15 y 40 años. ${ }^{7}$ Esta descripción se ajusta a la de las víctimas de Merino et al. (2013). Tanto la búsqueda de estas personas como su sustracción de una vida normal conllevan una serie de costos económicos difíciles de cuantificar. Mediante un esfuerzo conjunto de la Agencia de los Estados Unidos para el Desarrollo (USAID, por sus siglas en inglés), Enfoque DH y Fundación GEA, se estimó que se deben presupuestar 455 millones de pesos al año para gastos en personal

6 Consultado el 25 de marzo de 2019 en https://www.wsj.com/articles/its-acrisis-of-civilization-in-mexico-250-000-dead-37-400-missing-1542213374

7 Consultado el 25 de marzo de 2019 en https://www.jornada.com. $\mathrm{mx} / 2018 / 06 / 02 /$ politica/003n1pol 
y equipo para la búsqueda de personas desaparecidas y garantizar los derechos de las víctimas de tortura. ${ }^{8}$

Finalmente, otra dimensión humana de esta crisis humanitaria es la de los desplazamientos forzados. Basu y Pearlman (2017) estiman el efecto de la guerra contra el narco en la migración interna y la internacional. Con el fin de identificar el efecto causal de la guerra, utilizan como variables instrumentales los decomisos de cocaína en Colombia y los kilómetros de carreteras federal en el estado o el municipio. La idea detrás del instrumento es que tanto los decomisos de drogas como la disponibilidad de una red carretera de calidad hacen más lucrativo el tráfico de drogas y, por tanto, la lucha por plazas o rutas de transporte. Para la estimación, utilizan datos del Censo de Población 2010 y de la Encuesta Nacional de Ocupación y Empleo (ENOE). Estos autores encuentran una relación poco robusta entre la guerra y la migración interna o la internacional. Por ejemplo, en lo que se refiere a la migración interna, seńalan que al nivel estatal un aumento en la violencia disminuye la migración, mientras que al nivel municipal no encuentran ninguna relación estadísticamente significativa. En cuanto a la migración internacional, al nivel estatal hay una relación positiva con la migración, mientras que en el ámbito municipal la relación es negativa. Ante la falta de claridad de estos resultados no es posible concluir que no hay evidencia de una relación causal entre la migración y el nivel de violencia.

Por su parte, Arceo-Gómez (2013) estimó el efecto de la violencia del crimen organizado en la migración internacional entre municipios fronterizos. Esta selección de la muestra se debió a dos cuestiones. Primero, los municipios fronterizos son los que experimentaron el aumento más marcado en la tasa de homicidios. Segundo, los habitantes de la frontera tienen cierta facilidad para viajar a Estados Unidos con sus tarjetas de cruce fronterizo e instalarse en una franja de $25 \mathrm{~km}$ más allá de la frontera. La estimación utiliza datos sobre migrantes de la American Community Survey 2005-2010 y del County Business Pattern de Estados Unidos, así como datos de homicidios y población del INEGI. A partir de un modelo de efectos fijos se encuentra que hubo un aumento en la migración internacional de mexicanos con universidad o más. Sin embargo, el artículo no provee una forma de estimar el número de migrantes desplazados por la violencia y no es representativo al nivel nacional, sino solo de los municipios fronterizos.

8 Consultado el 30 de marzo de 2019 en https://www.cuantoparaencontrarlos. org/ 
El rango de resultados presentado en Basu y Pearlman (2017) y Arceo-Gómez (2013) se puede deber a distintos factores. Primero, dados los datos utilizados por los primeros, ellos no logran observar a hogares que migraron completos; esto es, solo identifican al menos que un migrante y un miembro del hogar permaneció en México. Otro factor adicional es que ambos artículos se enfocan en distintas submuestras: Arceo-Gómez (2013) se enfoca en municipios que vivieron un aumento muy marcado de la violencia, mientras que Basu y Pearlman (2017) utilizan datos de todo el país. Los resultados de Atuesta y Paredes (2016) aportan una explicación adicional. Ellos dividen a los migrantes internos en aquellos que migran desde estados no violentos por razones económicas (migrantes económicos) y aquellos que lo hacen desde entidades violentas a no violentas (desplazados internos). Basados en estos dos grupos, estiman el diferencial salarial compensatorio: ${ }^{9}$ los migrantes económicos están dispuestos a migrar a un estado violento si reciben un aumento de $25 \%$ en su salario; mientras que los desplazados están dispuestos a sacrificar $15 \%$ de su salario con tal de vivir en una entidad no violenta. La presencia de estos diferenciales salariales compensatorios podría explicar la aparente desconexión entre violencia y migración hallada en Basu y Pearlman (2017), dado que puede haber migración hacia estados violentos, y también los resultados de Arceo-Gómez (2013), quien se concentra en desplazados internacionales.

\subsection{Efectos de la violencia criminal en la actividad económica}

El principal reto empírico es lograr atribuirle, de manera exclusiva, a eventos violentos un cambio en la actividad económica. En primer lugar, esta atribución causal se dificulta porque las regiones donde se desatan hechos delictivos difieren sistemáticamente de las zonas donde no hay violencia. Por ejemplo, es posible que, para empezar, estas regiones tengan un menor potencial de crecimiento y que al comparar los resultados económicos de regiones violentas con aquellas no violentas atribuyamos al crimen la diferencia en las condiciones de desarrollo iniciales.

9 El diferencial salarial compensatorio es lo que el individuo está dispuesto a ceder de su salario con tal de acceder a mejores condiciones salariales (en este contexto, al migrar a una zona más segura). O bien, el salario adicional que el individuo demanda por exponerse a peores condiciones laborales (en este contexto, para migrar a una zona más insegura). 
En segundo lugar, es difícil atribuir causalidad si la falta de crecimiento económico incide, a su vez, en el desencadenamiento de actividades criminales; esto es, existe causalidad inversa entre resultados económicos y crimen. De acuerdo con el modelo de Becker (1968), uno de los determinantes de cometer delitos es la diferencia entre los beneficios de participar en actividades legales e ilegales. ${ }^{10}$ Así, si hay poco desarrollo económico, bajos salarios o altos niveles de desempleo, la probabilidad de que se comentan delitos aumenta. Esta relación cuenta con sustento empírico en otros países (Mustard, 2010). De Hoyos et al. (2016) encuentran que existe una relación positiva entre la proporción de jóvenes que ni estudian ni trabajan (ninis) en el estado y la tasa de homicidios entre 2007 y 2013.

Los costos económicos de la violencia criminal disparada por la guerra contra el narco han sido estimados por varios autores; entre ellos Robles et al. (2015) abordan el costo económico de la violencia desatada por el tráfico de drogas entre 2006 y 2010. Para tratar de identificar su efecto causal en resultados económicos, este artículo utiliza dos metodologías. Primero, instrumenta la tasa de homicidios mediante la incautación de drogas en Colombia y la distancia del municipio al punto de entrada a Estados Unidos más cercano. La idea detrás de este instrumento es que la incautación de drogas en Colombia eleva los precios en Estados Unidos y hace que este mercado sea aún más atractivo para los capos mexicanos. Por su parte, la distancia a los puntos de entrada aproxima el valor de la plaza para los capos. Esta variación exógena (que no depende de las condiciones de la economía mexicana) en el valor de las distintas plazas impacta, a su vez, en la tasa de homicidios dada la competencia entre los capos. La segunda metodología de este artículo es la de controles sintéticos desarrollada por Abadie y Gardeazabal (2003), en la cual se construye un contrafactual a partir de las regiones que no fueron tan afectadas. Por tanto, el efecto causal de la violencia criminal extrema es la diferencia entre la actividad económica observada del municipio y la actividad económica del contrafactual. Otra novedad de este artículo es que utiliza el consumo de energía eléctrica como una variable proxy de la actividad económica al nivel municipal, resolviendo así el problema de ausencia de series de datos anuales del рів municipal. Los resultados del artículo se resumen en la Tabla 2.

${ }^{10}$ Dados ciertos supuestos del modelo, Becker (1968) descarta que en el margen las actividades ilegales reporten beneficios por encima de las actividades legales. Sin embargo, esto no necesariamente describe la conducta promedio de los individuos y los supuestos no necesariamente se sostienen. 
Balmori de la Miyar (2016) recurre a otra estrategia de identificación para la estimación del efecto causal de la guerra contra las drogas en el crecimiento económico. El objetivo es estimar el impacto de la violencia criminal, medida por la tasa de homicidios, en el PIB estatal. Para ello, explota la evolución geográfica de las operaciones conjuntas que se llevaron a cabo como parte de la estrategia de la guerra contra el narco. Así, utiliza información de cuándo iniciaron las operaciones conjuntas en el estado y de su intensidad, medida por el número de decomisos de drogas o de detenciones de personas por cada 100 mil habitantes en la entidad. La interacción de estas dos variables es una variable continua de las intervenciones en la guerra. Su primer objetivo es estimar el efecto de estas intervenciones en la tasa de homicidios, encontrando que $30.8 \%$ de la variación en la tasa de homicidios relacionados con las drogas se debió a la guerra contra el narco. Para estimar el efecto en el PIB utiliza controles sintéticos al nivel estatal. Encuentra que las operaciones contra el narco redujeron el PIB per cápita estatal en $0.5 \%$ en las entidades tratadas (Chihuahua, Durango, Guerrero, Michoacán y Sinaloa).

Otros artículos se han centrado en los efectos de la guerra contra el narco en variables agregadas distintas del pIB. Aunque este no era su principal objetivo, Dell (2015) encontró que esta provocó una caída de 1.3 puntos porcentuales en la tasa de participación laboral femenina (de una media de 51\%) y una reducción en los ingresos laborales del sector informal de $2.3 \%$ en los municipios tratados, que en su caso son aquellos con una ruta de tráfico de drogas, donde estas se predicen con base en un modelo que minimiza los costos de transporte de los estupefacientes.

En esta misma línea, Velásquez (2019) estima el efecto de la violencia criminal en resultados laborales de las personas. Para ello, ella explota los datos en panel de la Encuesta Nacional sobre Niveles de Vida de los Hogares (EnNViH) de las rondas 2005 y 2009-2012. El supuesto clave es que, al nivel hogar, el marcado incremento en la tasa de homicidios fue inesperado, así que se puede considerar como un evento exógeno. Ella encuentra que los ingresos por hora de hombres autoempleados cayeron en $15 \%$, mientras que sus ingresos laborales totales lo hicieron por $11.4 \%$. En el caso de las mujeres, encuentra que las que estaban autoempleadas disminuyeron su participación laboral en 14\% y sus ingresos laborales en 33\%.

Finalmente, mientras que la literatura citada anteriormente se enfocó en medir el efecto contemporáneo de la violencia criminal en el PIB, Enamorado et al. 
(2014) encuentran que la tasa de homicidios relacionados con las drogas tiene un efecto negativo en el crecimiento durante el período 2005 a 2010. Específicamente, ellos estiman que un incremento de una desviación estándar en la tasa de homicidios por cada 100 mil habitantes provoca una disminución en la tasa de crecimiento de 0.20 puntos porcentuales. Así, un municipio con una tasa de homicidios igual a 90 disminuiría su crecimiento económico en un punto porcentual durante este período.

La Tabla 2 muestra un resumen de todos estos resultados en la actividad económica.

\section{Tabla 2. Efectos de la violencia criminal en la actividad económica}

\section{Artículo}

Robles et al. (2015)

\section{Principales resultados}

Variables instrumentales: un aumento en 10 homicidios por cada 100 mil habitantes:

Reduce \% de población empleada en 2.22 pp.

Aumenta \% de población desempleada en 1.48 pp.

Reduce \% de población con negocio propio en $0.4 \mathrm{pp}$.

Reduce \% de población autoempleada en $0.48 \mathrm{pp}$.

Reduce el ingreso laboral en $12 \%$

Controles sintéticos: Entre 2006 y 2010, los municipios con aumentos drásticos en la violencia consumieron $6.8 \%$ menos energía per cápita por año en promedio.

Ratio Рів/Consumo de energía: $\$ 45.75$ por MW/hr.

Media del consumo de energía pretratamiento: $1.2 \mathrm{MW} / \mathrm{hr}$.

Disminución del consumo de energía: $0.0816 \mathrm{MW} / \mathrm{hr}$.

Disminución en el PIB per cápita: $\$ 3.73$ pesos per cápita en los municipios tratados.

Balmori de la Miyar (2016) Controles sintéticos: Los estados tratados fueron Chihuahua, Durango, Guerrero, Michoacán y Sinaloa.

Disminución en el piв per cápita de los estados tratados de $0.5 \%$ durante 2007-2012. 
Dell (2015)

Velásquez (2019)
Variables instrumentales: Ruta predicha por un modelo de redes de distribución

Disminuye la tasa de participación laboral femenina $1.3 \mathrm{pp}$.

Disminuyen los ingresos laborales en el sector informal en 2.3\%.

Datos en panel con efectos fijos al nivel individual (entre otros):

Disminuye el salario por hora de autoempleados hombres en $15 \%$.

Disminuyen los ingresos laborales de autoempleados hombres en $11.4 \%$.

Disminuye la tasa de participación laboral femenina de las antes autoempleadas en $14 \%$.

Disminuyen los ingresos laborales de autoempleadas en 33\%.

\section{Datos en panel al nivel municipal: estiman la convergencia- entre} municipios.

Un aumento de una desviación estándar ( 8 homicidios por drogas por c/ $100 \mathrm{mil}$ ) disminuye la tasa de crecimiento en $0.20 \mathrm{pp}$.

Un municipio con una tasa de homicidios por drogas de 90 por $\mathrm{cl}$ 100 mil disminuye su tasa de crecimiento en $1 \mathrm{pp}$.

Fuente: Elaboración propia con base en la literatura citada.

\subsection{La relación entre la impunidad y la violencia criminal: efectividad y legitimidad del gobierno}

Una vez establecidos los costos económicos de la violencia criminal, la cual ha recibido mucha atención en la literatura, necesitamos establecer cómo se relaciona esta violencia (la tasa de homicidios) con la impunidad. La medición de la impunidad es muy compleja. Para el caso de México, Ortiz y Vázquez (2019) proponen varias medidas de la impunidad basadas en la denuncia (relacionado con la cifra negra), las acciones penales (eficacia del Ministerio Público) y las sentencias (eficacia del aparato de justicia). Así, miden la impunidad como 100 menos el porcentaje de personas sentenciadas (denuncias sobre las que se reporta algo distinto a "no sucedió nada”) respecto de: 1) el total de actos delictivos (impunidad en delitos), 2) el total de delitos denunciados (impunidad en denuncias), y 3) el total de averiguaciones previas abiertas (impunidad en investigaciones). También utilizan como medida de impunidad el total de homicidios investigados respecto del total de homicidios y el porcentaje de casos de homicidio doloso cerrados en primera instancia respecto del total de los registrados. 
Basándose en estas medidas de impunidad ellos presentan los resultados resumidos en la Tabla 3. Estas estimaciones se obtuvieron de una regresión con efectos fijos en el ámbito estatal que controla por PIB y población estatal con datos de 2010 a 2016. Se puede observar que un aumento en la impunidad en un punto porcentual en delitos aumenta en 173 el número de desaparecidos, mientras que un aumento en un punto porcentual en la tasa de investigaciones disminuye en 181.8 el número de desplazados.

\section{Tabla 3. Correlación de la impunidad con desapariciones, desplazados y homicidios}
Desaparecidos
Desplazados
Homicidios

Impunidad en delitos

Impunidad en denuncias

Impunidad en investigaciones

Tasa de investigaciones

Tasa de sentencias
173.0*

$38.8^{*}$

$25.1^{*}$

Fuente: Elaboración propia con base en los resultados de Ortiz y Vázquez (2019).

Se presentan los coeficientes de las regresiones que controlan por efectos fijos al nivel estatal, piB estatal y población del estado. Las unidades de las medidas de impunidad tienen un rango de 0 a 100 puntos porcentuales. Las víctimas están en números absolutos. * valor-p<0.05.

En cuanto a los resultados para homicidios, los autores también utilizan la tasa de investigaciones de casos de homicidios respecto del total. Dado que estos aumentaron y es muy posible que la capacidad del aparato judicial se haya mantenido constante, esta medida está directamente relacionada con la guerra contra el narco durante el período que se estudia. Además, dado que los homicidios se encuentran tanto en la variable dependiente como la independiente, esta regresión puede estar capturando una correlación mecánica entre la medida de impunidad y el número de homicidios. Adicionalmente, todas las regresiones controlan por el PIB y la población. Si bien, este control es muy intuitivo, de la revisión de literatura anterior sabemos que el PIB se ha visto afectado por la guerra y también la población de las localidades (ya sea vía homicidios, desapariciones o desplazamientos forzados). Por ello, también se recurrirá a otros resultados que estiman la relación entre la eficacia del gobierno o la legitimidad del gobierno (las cuales se relacionan con la impunidad) y la tasa de homicidios.

Azfar (2005) estudia la relación entre la efectividad del gobierno y la tasa de homicidios en una sección cruzada de países, utilizando la medida de efectividad 
del gobierno compilada por el World Bank Institute. ${ }^{11}$ El autor explica que los gobiernos efectivos pueden tener mayor habilidad para prevenir los homicidios y mayor credibilidad a ojos de sus electores. Dado que la efectividad del gobierno se puede ver comprometida por altas tasas de violencia en un país, Azfar instrumenta la efectividad con una combinación de variables históricas de colonización, asentamientos de colonizadores y democracia. Los resultados apuntan a que un cambio de una desviación estándar en la efectividad del gobierno (ir de México a Costa Rica, por ejemplo) reduciría la tasa de homicidios a la mitad.

Por otra parte, Nivette y Eisner (2013) estudian si la legitimidad política de un gobierno predice la tasa de homicidios en una sección cruzada de países. La falta de legitimidad podría tener un impacto en los homicidios mediante tres mecanismos: 1) ruptura del control social dada la falta de conformidad social con las normas; 2) desconfianza en el sistema judicial para resolver conflictos interpersonales, y 3) la incapacidad de los Estados ilegítimos de asignar recursos de forma justa. El segundo mecanismo se encuentra fuertemente relacionado con la impunidad: sus altos niveles restan legitimidad al Estado. Los autores encuentran que un ca mbio de una desviación estándar en el índice de legitimidad disminuiría la tasa de homicidios en 34\%. Si México tuviese el nivel de legitimidad de Uruguay (el país mejor rankeado de Latinoamérica), la tasa de homicidios disminuiría en 71.7\%.

Finalmente, Huebert y Brown (2019) elaboran un análisis entre países sobre la relación del debido proceso con los homicidios. ${ }^{12}$ El debido proceso otorga legitimidad al Estado y le da confianza a los ciudadanos de resolver sus disputas a través del sistema judicial. Esto disminuye la impunidad en la denuncia y, por tanto, le permite al Estado perseguir y castigar el crimen con mayor efectividad, lo cual refuerza su legitimidad y la confianza en las instituciones judiciales. Los autores

${ }^{11}$ Esta medida agrupa en un índice "la calidad de la provisión de servicios públicos, la calidad de la burocracia, la competencia de los servidores públicos, la independencia del servicio público de presiones políticas y la credibilidad del compromiso de los gobiernos con sus políticas" (Azfar, 2005, p. 1, traducción propia).

12 "El debido proceso se refiere a los requerimientos legales de que un estado debe respetar los derechos legales de sus ciudadanos" (Huebert y Brown, 2019, p. 190, traducción propia), tales como: "la presunción de inocencia y la oportunidad de someter e impugnar evidencia en procedimientos públicos; la libertad de arrestos y detenciones arbitrarios, tortura y tratamiento abusivo; y acceso a consejería legal y traductores" (World Justice Project, 2016, en Huebert y Brown, 2019, p.190, traducción propia). 
explican que el debido proceso incluso invita a la cooperación, por parte de los ciudadanos, con las fuerzas de seguridad para hacer valer las reglas de convivencia social. A partir de una regresión lineal del debido proceso, controlando por el nivel de impunidad, los autores encuentran que un cambio en una desviación estándar en el índice de debido proceso está correlacionado con una reducción del $73 \%$ en la tasa de homicidios.

La impunidad posiblemente se encuentra muy correlacionada con otras medidas de calidad institucional y, por ello, carece de valor explicativo en la regresión: ya no aporta más información sobre la capacidad del Estado de prevenir el delito. Por ello, es posible que la calidad de las instituciones sea una mejor medida de la capacidad del gobierno de hacer valer las leyes. Si tomamos la medida más conservadora de estos resultados, llevar al gobierno mexicano a los niveles de efectividad del gobierno costarricense implicaría disminuir la tasa de homicidios a la mitad. Este será el resultado que tomaremos del efecto de la impunidad (medido aquí como calidad de las instituciones) en la tasa de homicidios.

\section{Estimación del costo de la violencia criminal}

\subsection{Costo de la pérdida de vidas y desaparecidos}

A continuación, presentamos el procedimiento que utilizado para estimar el costo de las vidas humanas. Para calcular el número de víctimas por género, grupo de edad y nivel educativo usamos los datos de certificados de defunción del Sinais. ${ }^{13}$ La Gráfica 2 presenta un comparativo de los homicidios estimados con los homicidios de la base de datos del Secretariado Ejecutivo del Sistema Nacional de Seguridad Pública (SNSP). La Tabla 4 muestra la estimación del número de víctimas por género y nivel educativo dados estos supuestos. La línea sólida presenta los datos del SNSP. La línea gris oscuro con puntos y guiones presenta el total de homicidios de los datos del Sinais. Aquí se incluyen todas las clasificaciones de muertes por circunstancias externas clasificadas como agresiones, más aquellas lesiones infligidas en actos militares o de guerra. La línea gris claro punteada presenta los homicidios relacionados con el modus operandi del narco, ${ }^{14}$ y aquellos

${ }^{13}$ Disponible en http://www.dgis.salud.gob.mx/contenidos/basesdedatos/ std defunciones gobmx.html

${ }_{14}$ Estas agresiones incluyen: ahorcamiento, estrangulamiento y sofocación; ahogamiento y sumersión; disparo de arma corta; disparo de rifle, escopeta y arma 
que sucedieron en actos militares o de guerra del Sinais. Dada la similitud de esta última serie con los datos del SNSP a partir de 2010, utilizaremos estos homicidios para delimitar el perfil de las víctimas durante todo el periodo.

Siguiendo a Merino et al. (2013), para establecer el perfil de las víctimas, dividimos a la población por género, cinco grupos de edad y cinco niveles educativos. Así, obtuvimos el total de homicidios relacionados con el narco para el período que va de 2007 a 2015 para cada grupo y el total del período. ${ }^{15}$ Con estas cantidades estimamos las proporciones presentadas en la Tabla 4. Más de $90 \%$ de las víctimas han sido hombres y más de $70 \%$ de las víctimas son hombres que no terminaron la educación media superior. También se observa que $86 \%$ son hombres entre 18 y 40 años.

\section{Gráfica 2. Comparativo del número de homicidios}

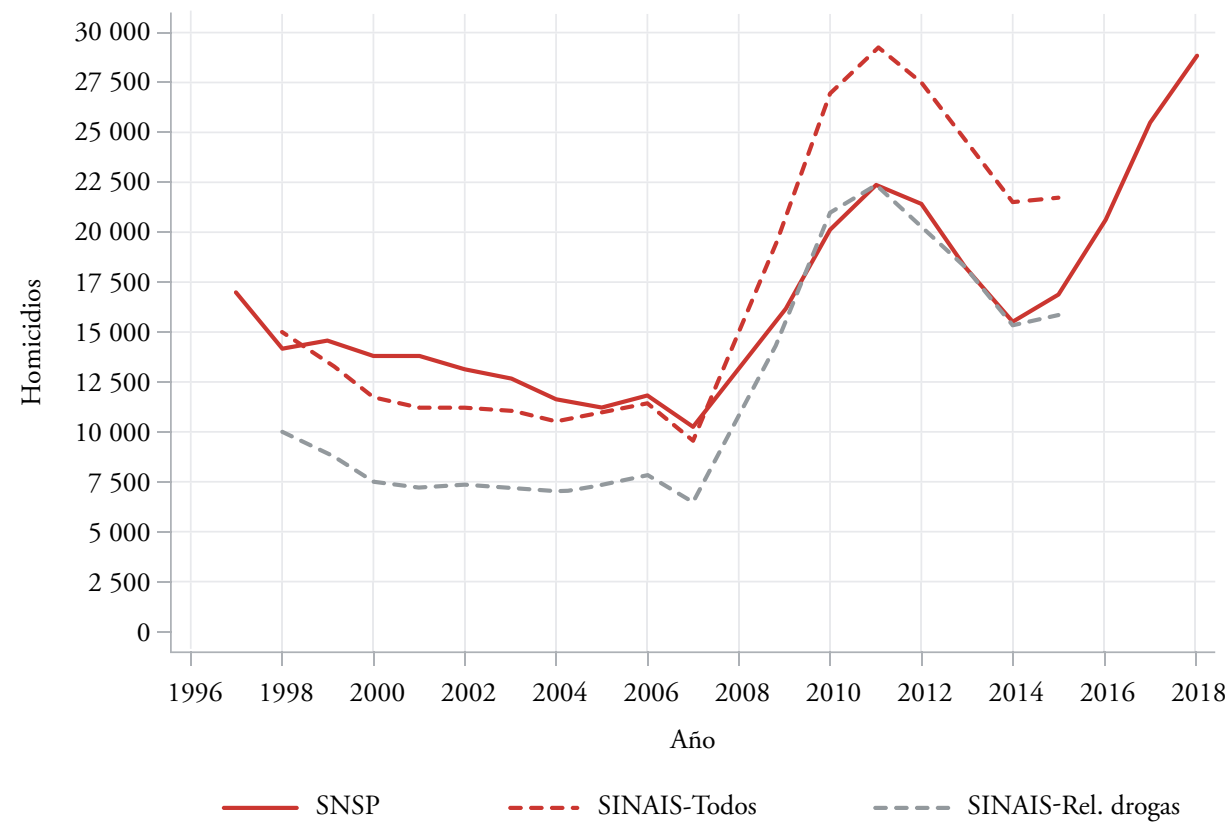

Fuente: Elaboración propia con base en datos del Sinais y del sNsp.

larga; disparo de otras armas de fuego, y las no especificadas; con material explosivo; y con humo, fuego y llamas.

${ }^{15}$ Se eliminaron todas aquellas observaciones donde el género, la edad o el nivel educativo estaban indeterminados. 
Tabla 4. Perfil de las víctimas de homicidio: 2007-2015

\begin{tabular}{|c|c|c|c|c|}
\hline $\begin{array}{l}\text { Menores } \\
\text { de } 12 \text { ańos } \\
(\%)\end{array}$ & $\begin{array}{c}12-17 \\
\text { años } \\
(\%)\end{array}$ & $\begin{array}{c}18-25 \\
\text { ańos } \\
(\%)\end{array}$ & $\begin{array}{c}26-40 \\
\text { ańos } \\
(\%)\end{array}$ & $\begin{array}{c}\text { Más de } \\
40 \text { ańos } \\
(\%)\end{array}$ \\
\hline
\end{tabular}

\section{A. Hombres}

$\begin{array}{lcccccc}\text { Menos de primaria completa } & 0.32 & 0.56 & 1.76 & 5.46 & 8.49 & 16.59 \\ \text { Primaria completa } & 0.02 & 1.78 & 5.12 & 12.21 & 8.09 & 27.22 \\ \text { Secundaria completa } & & 1.28 & 6.01 & 13.65 & 6.30 & 27.24 \\ \text { Preparatoria completa } & & 0.29 & 2.49 & 6.11 & 3.43 & 12.32 \\ \text { Universidad o superior } & & & 0.59 & 2.93 & 3.38 & 6.89 \\ \text { Total } & 0.34 & 3.91 & 15.97 & 40.35 & 29.69 & 90.27\end{array}$

\section{B. Mujeres}

$\begin{array}{lllllll}\text { Menos de primaria completa } & 0.21 & 0.11 & 0.16 & 0.42 & 1.29 & 2.19 \\ \text { Primaria completa } & 0.01 & 0.37 & 0.41 & 0.91 & 0.89 & 2.59 \\ \text { Secundaria completa } & & 0.32 & 0.66 & 1.02 & 0.60 & 2.60 \\ \text { Preparatoria completa } & & 0.09 & 0.37 & 0.51 & 0.35 & 1.32 \\ \text { Universidad o superior } & & & 0.15 & 0.47 & 0.41 & 1.03 \\ \text { Total } & 0.22 & 0.89 & 1.75 & 3.33 & 3.55 & 9.73\end{array}$

Fuente: Estimación propia basada en los datos del Sinais.

Los datos del Sinais abarcan hasta 2015, mientras que los datos del sNSP llegan hasta 2018. Además, en la limpieza de los datos del Sinais perdemos alrededor de $30 \%$ de los asesinatos debido a que no se reporta el género, la edad o el nivel educativo. ${ }^{16}$ Entonces, para lograr cubrir el mayor número posible de víctimas con los datos, imputamos el número de víctimas por género, grupo de edad y nivel educativo del período 2007-2018. Estas imputaciones se estimaron con los datos de homicidios del SNSP y las proporciones por celda estimadas del Sinais (Tabla 4). Los resultados de esta imputación se presentan en la Tabla 5. De esta manera logramos mantener a las 228957 reportadas por el SNSP.

${ }^{16}$ Con los datos del Sinais solo contamos con alrededor de 190 mil asesinatos, lo cual representa $83 \%$ de los homicidios reportados por el snsp. La Figura 2 no elimina a las observaciones con valores faltantes en estas características del Sinais y por ello los homicidios identificados como del narco se aproximan mejor a las cifras del snsp. 
Tabla 5. Homicidios por celda: 2007-2018

$\begin{array}{crrrr}\text { Menores de } & 12-17 & 18-25 & 26-40 & \text { Más de } \\ 12 \text { ańos } & \text { ańos } & \text { ańos } & \text { ańos } & 40 \text { años }\end{array}$

\section{A. Hombres}

$\begin{array}{lccccc}\text { Menos de primaria completa } & 740 & 1272 & 4041 & 12492 & 19442 \\ \text { Primaria completa } & 44 & 4084 & 11714 & 27946 & 18534 \\ \text { Secundaria completa } & - & 2939 & 13769 & 31243 & 14414 \\ \text { Preparatoria completa } & - & 659 & 5698 & 13995 & 7864 \\ \text { Universidad o superior } & - & - & 1351 & 6701 & 7731 \\ \text { Total } & 783 & 8953 & 36573 & 92377 & 67985\end{array}$

\section{B. Mujeres}

$\begin{array}{lccccc}\text { Menos de primaria completa } & 475 & 249 & 374 & 961 & 2963 \\ \text { Primaria completa } & 20 & 856 & 945 & 2085 & 2029 \\ \text { Secundaria completa } & - & 728 & 1519 & 2328 & 1382 \\ \text { Preparatoria completa } & - & 202 & 845 & 1171 & 807 \\ \text { Universidad o superior } & - & - & 332 & 1076 & 939 \\ \text { Total } & 494 & 2035 & 4015 & 7620 & 8121\end{array}$

Total de homicidios entre $\quad 228957$ 2007 y 2018 :

Una vez determinado el número de víctimas por cada celda, necesitamos definir alguna medida del costo económico de ellas. Por eso, suponemos que el costo económico de una persona es la pérdida de flujo salarial de acuerdo con su grupo de edad y nivel educativo. ${ }^{17}$ Dado que en el perfil de las víctimas no se puede identificar el estatus laboral, hacemos una generalización y suponemos que todos tienen el potencial de ganar el salario promedio que gana en su grupo de género, edad y nivel educativo. La Tabla 6 muestra la estimación de los ingresos laborales

17 Esta medida es obviamente muy limitada del valor de una persona. En la valoración de una vida hay una serie de elementos subjetivos que, en muchos casos, ni siquiera son medibles. En economía, la valoración de una vida a través de la pérdida del flujo salarial es común. Otra medida que usamos los economistas es el valor de una vida estadística, pero se ha visto que al igual que la pérdida salarial, este valor está correlacionado positivamente con el nivel de ingresos de un país. Además, no se tienen estimaciones del valor de una vida estadística en México. 
promedio en 2005. Utilizamos este año dado que la evidencia muestra que la violencia criminal afectó los ingresos laborales de las personas y 2005 es un período previo al inicio de la guerra contra el narco y el primer año de levantamiento de la ENOE, la cual es representativa al nivel nacional. Adicionalmente, no consideramos a los individuos que no están empleados para la estimación de este promedio. ${ }^{18}$ Esto se debe a que no conocemos el estatus laboral de las víctimas y es mejor asumir que todas tienen el mismo potencial salarial de acuerdo con su género, edad y nivel educativo. ${ }^{19}$

\section{Tabla 6. Ingresos laborales anuales promedio por género, nivel educativo y grupo de edad}

\section{5-17 años 18-25 años 26-40 años Más de 40 años}

\section{A. Hombres}

$\begin{array}{lcccc}\text { Menos de primaria completa } & 25561 & 33248 & 38174 & 36269 \\ \text { Primaria completa } & 25713 & 38230 & 45940 & 50211 \\ \text { Secundaria completa } & 26325 & 39570 & 53663 & 61830 \\ \text { Preparatoria completa } & 29644 & 41826 & 67806 & 82887 \\ \text { Universidad o superior } & 27377 & 61092 & 108161 & 140857\end{array}$

\section{B. Mujeres}

$\begin{array}{lllll}\text { Menos de primaria completa } & 20394 & 23638 & 23350 & 21856 \\ \text { Primaria completa } & 21748 & 27689 & 27623 & 31072 \\ \text { Secundaria completa } & 22740 & 30761 & 34996 & 42929 \\ \text { Preparatoria completa } & 24376 & 34983 & 50290 & 64820 \\ \text { Universidad o superior } & 34443 & 55699 & 79968 & 103418\end{array}$

Fuente: Elaboración propia con base en datos de la ENOE, 2005.

Se presentan los salarios laborales promedio en el ańo por género, nivel educativo y grupo de edad del trabajador. La ENOE reporta salarios de individuos de 15 ańos o más. Se excluye de la muestra de estimación a las personas que no trabajan. Estos promedios utilizan los factores de expansión de la ENOE.

${ }^{18}$ Se ha documentado que la tasa de respuesta a la pregunta sobre los ingresos laborales ha disminuido en el tiempo (Campos-Vazquez 2013). En este documento no se hizo ningún tipo de imputación salarial para corregir este problema.

${ }^{19} \mathrm{El}$ problema con este supuesto es precisamente que se asumen que quienes no trabajan tienen el mismo potencial. La literatura en economía laboral ha encontrado que las personas se seleccionan positivamente para entrar al mercado laboral. Esto es, aquellos que no trabajan de hecho tienen menos potencial salarial que aquellos que sí trabajan, lo cual conduce a un sesgo de selección. 
El siguiente paso en la estimación es obtener el valor presente de los flujos salariales anualizados. Para ello suponemos que los salarios no cambian en términos reales en el tiempo para cada grupo de edad y nivel educativo, pero que los individuos acceden a un mayor salario conforme envejecen de acuerdo con el perfil mostrado en la Tabla 6. Para cada grupo de edad de las víctimas, tomamos como referente para arrancar la estimación del valor presente al promedio de edad dentro del grupo. Formalmente, para cada sexo $s$, grupo de edad $g$, y nivel de escolaridad $n$, estimamos el siguiente valor presente:

$$
V P_{s g n}=\sum_{i=1}^{5} \sum_{t>\mu_{s g}}^{g_{i}^{\max }} \frac{\bar{W}_{s g_{i} n}}{(1+r)^{\left(t-\mu_{s g}\right)^{\prime}}}
$$

donde $\mu_{s g}$ es el promedio de edad del grupo de edad de la víctima de homicidio; $g_{i}^{\text {max }}$ es la cota superior de edad de cada grupo de edad $i=\{$ Menores de 12,12-17,18-24,25-39, Más de 40 $\} ; t$ es el tiempo o la edad que tendría el individuo cada ańo si continuara con vida; $\bar{W}_{s g_{i} n}$ es el salario promedio anual de un individuo de sexo $s$, que se encuentra viviendo en el grupo de edad $g_{i}$, y con nivel de escolaridad $n$; y $r$ es la tasa de interés. En la estimación se toma la tasa de interés de la interbancaria trimestral, anualizada promedio de 2005, la cual es igual a $9.6135 \% .{ }^{20}$ De nuevo, este año se toma como una base preguerra en la estimación. La cota superior de edad del grupo de mayores de 40 años es la esperanza de vida por género. Suponemos que la esperanza de vida de las mujeres es de 78 ańos y la de los hombres de 72 ańos, las cuales reflejan la esperanza de vida estimada en 2010 (Canudas-Romo et al., 2015). ${ }^{21}$ Por simplicidad, estamos

Una alternativa a este supuestos es hacer una corrección por selección muestral tipo Heckman (1979). Adicionalmente, una medida solo salarial no considera el valor de la producción doméstica, la cual se encuentra dominada por las mujeres, pero es difícil producir una medición del valor de dicha producción. Se debe mencionar que este cálculo no considera el lugar de residencia de las víctimas y las consiguientes diferencias salariales entre las distintas regiones del país, hecho que podría considerarse para futuras investigaciones en el tema.

${ }^{20}$ Hacemos el supuesto de que esta tasa refleja mejor la tasa de intercambio entre presente y futuro que las tasas de interés prevalentes en el mercado de créditos, las cuales reflejan, además, la tasa de riesgo de los clientes y las comisiones del banco, entre otros.

${ }^{21}$ Más adelante muestro un ejercicio del costo de la pérdida de esperanza de vida. 
suponiendo implícitamente que todos los grupos de edad de hombres y mujeres esperan vivir hasta los 72 o 78 ańos, respectivamente. Cabe aclarar que $\bar{W}_{s g_{i} n}$ es igual a cero hasta los 11 años. Se asume que los individuos entre 12 y 14 años tienen un salario promedio equivalente al de su grupo de edad (12-17 años), aunque estas edades ni siquiera son consideradas en el levantamiento de la ENOE. ${ }^{22}$

A manera de ejemplo, para una víctima mujer en el grupo de edad de 12 a 17 años con nivel de escolaridad secundaria terminada, ${ }^{23}$ la expresión anterior sería:

$$
\begin{aligned}
V P_{s g n} & =\sum_{t>14}^{17} \frac{22,740}{(1+0.096135)^{(t-14)}}+\sum_{18}^{24} \frac{30,761}{(1+0.096135)^{(t-14)}}+\sum_{25}^{39} \frac{34,996}{(1+0.096135)^{(t-14)}} \\
& +\sum_{40}^{78} \frac{42,929}{(1+0.096135)^{(t-14)}}
\end{aligned}
$$

Los resultados por género, grupo de edad y nivel educativo se exponen en la Tabla 7. Siguiendo el mismo patrón que los salarios, el valor presente aumenta con el nivel educativo y es mayor para los hombres. También se observa que se incrementa con la edad hasta los 40 ańos y disminuye para las personas mayores de 40 años.

El último paso en la estimación del costo de los homicidios es multiplicar los valores de la Tabla 7 con los homicidios correspondientes de la Tabla 5 y elaborar la suma de los costos del total de asesinatos durante el período 2007-2018. Los resultados de esta última estimación se muestran en la Tabla 8. Elvalor presente total asciende a 135 miles de millones de pesos, lo cual representa $1.81 \%$ del piв de 2005. Sin embargo, esta cifra es engañosa ya que el crecimiento de una economía es compuesto. ${ }^{24} \mathrm{El}$ costo promedio simple anual en términos del PIB es de $0.1507 \% .{ }^{25}$ Haciendo un ejercicio a manera de ejemplo, supongamos que la

${ }^{22}$ La ENOE solo entrevista sobre cuestiones laborales a la población de 15 años y más.

23 La estimación está suponiendo que las víctimas menores de 15 años al menos alcanzarán a completar la secundaria, la cual representa la media de años de escolaridad en México.

24 Esto se debe a que el crecimiento se da sobre una cifra que está aumentado.

25 Esto resulta de dividir la suma de los valores presentes expuestso en la Tabla 7 divida entre el PIB nominal en 2005 y el número de años en que se produjo esta cantidad de homicidios (12 años). 
Tabla 7. Valor presente del individuo promedio por género nivel educativo y grupo de edad

$\begin{array}{crrrr}\begin{array}{c}\text { Menores de } 12 \\ \text { ańos }\end{array} & \begin{array}{c}12-17 \\ \text { ańos }\end{array} & \begin{array}{c}18-25 \\ \text { años }\end{array} & \begin{array}{c}26-40 \\ \text { años }\end{array} & \begin{array}{c}\text { Más de } 40 \\ \text { años }\end{array}\end{array}$

\section{A. Hombres}

\begin{tabular}{|c|c|c|c|c|c|}
\hline Menos de primaria completa & & 368789 & 407935 & 416999 & 341244 \\
\hline Primaria completa & & 426002 & 494805 & 533005 & 472420 \\
\hline Secundaria completa & 231670 & 468745 & 562142 & 637707 & 581740 \\
\hline Preparatoria completa & & & 684234 & 828392 & 779867 \\
\hline Universidad o superior & & & 1082801 & 1362453 & 1325296 \\
\hline
\end{tabular}

\section{B. Mujeres}

\begin{tabular}{lccccc} 
Menos de primaria completa & 254753 & 263621 & 255740 & 221674 \\
Primaria completa & 297325 & 319929 & 327846 & 315141 \\
\hline Secundaria completa & 174895 & 347287 & 393503 & 432648 & 435399 \\
Preparatoria completa & & 532306 & 636909 & 657429 \\
\hline Universidad o superior & & 847349 & 1014450 & 1048912
\end{tabular}

Fuente: Elaboración propia con base en los datos de la Tabla 6.

Se muestra el valor presente de los flujos de ingresos laborales anualizados. Para los menores de 18 años se asume que alcanzan el nivel de escolaridad promedio de los jóvenes de 18 a 24 años, el cual equivale a secundaria completa en esta Tabla. La tasa de interés es 9.6135 anual. Estas cantidades se encuentran estimadas a precios de 2005.

economía crece cada año al $3 \%,{ }^{26}$ y que el costo anual de la violencia es $0.1507 \%$. Supongamos que empezamos a contabilizar el efecto de estas muertes en el crecimiento a partir de 2019. La Gráfica 3 presenta el total de las pérdidas en el PIB partiendo de un índice normalizado a 1 en $2018 .{ }^{27}$ Se aprecia que para 2030 la economía habría crecido $2.48 \%$ más respecto de 2018 sin la pérdida acumulada de vidas de los últimos 12 años. Para 2040, la pérdida de crecimiento sería de $6.07 \%$ y para 2050 , de $11.79 \%$.

26 No podemos usar la tasa de crecimiento realizada en el período porque esta se encuentra afectada por la violencia criminal.

${ }^{27}$ La estimación parte de 2006 por simplicidad. Los supuestos implícitos son que todos los asesinatos fueron en 2006 y que todos se evalúan de acuerdo con el nivel de salarios y la tasa de interés promedio de 2005. El año de inicio de la estimación es irrelevante; podríamos iniciar la estimación en 2018 con los valores de 2005 para no confundir el valor económico de estas vidas con otros efectos de estas muertes en la economía. El punto para llevarnos de este análisis es lo que sucede con el paso del tiempo. 


\section{Tabla 8. Costo de las víctimas de homicidios}

Costo total de las vidas (millones de pesos)

135540

PIB nominal en 2005 (millones de pesos)

7496787.5

Costo simple en términos del PIв 2005

$1.81 \%$

Costo compuesto simulado tras 12 años

$2.48 \%$

Fuente: Elaboración propia (detalles en el texto).

Gráfica 3. Comparativo de la trayectoria de crecimiento del PIB con y sin homicidios

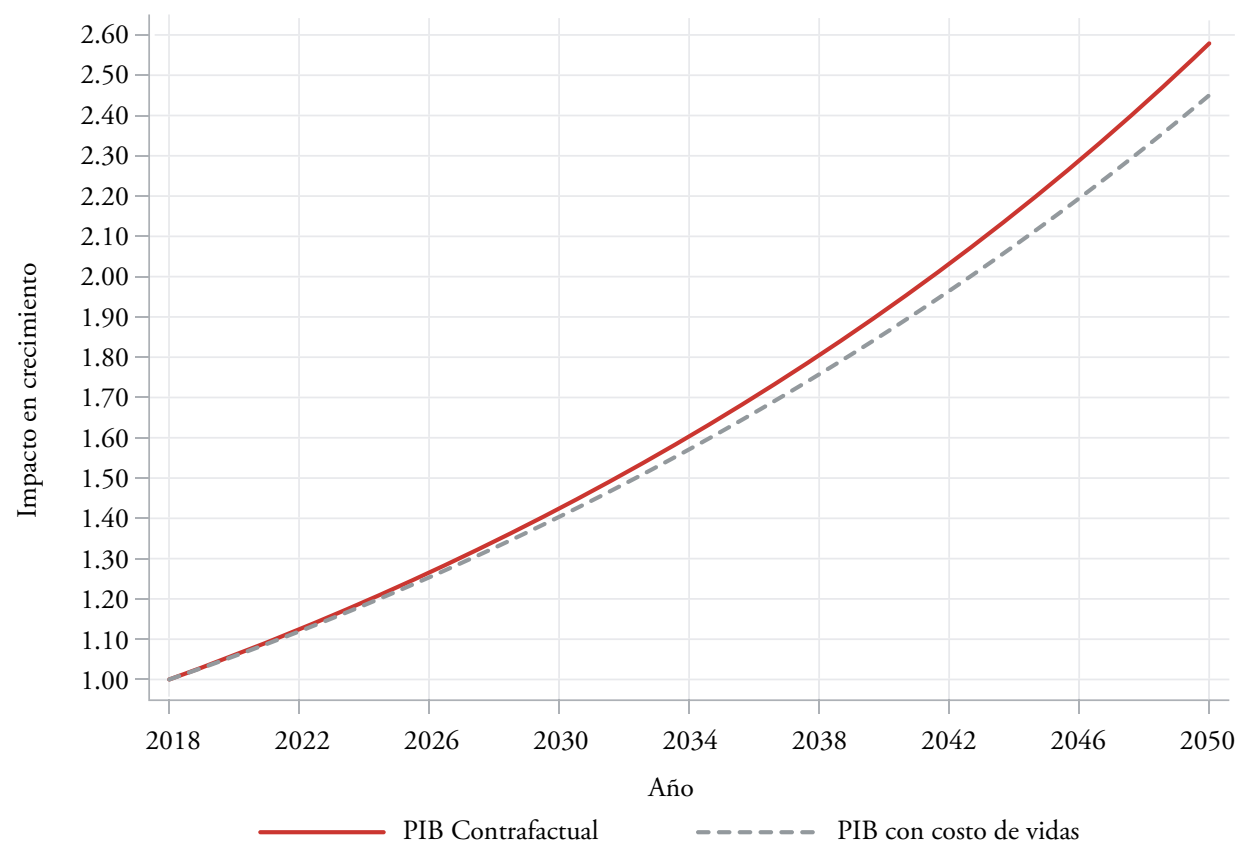

Fuente: Elaboración propia con base en una simulación del crecimiento.

Para el caso de las desapariciones se puede hacer un ejercicio similar. Si añadimos a los desaparecidos las víctimas de la Tabla 5 y suponemos que tienen el mismo perfil que las víctimas, entonces el costo con todo y desaparecidos en términos del pIB de 2005 asciende a $2.1 \%$. Una vez que consideramos una tasa de crecimiento compuesta, un costo anual promedio de la violencia igual a $0.1753 \%$ durante 
el primer año y el resto de los supuestos del ejercicio anterior, el costo en términos del PIB ascendería a 2.88\% de crecimiento acumulado en 2030. Además de estos, están los costos de encontrar a los desaparecidos. Como mencionamos en la revisión de la literatura, se estima que se requieren 455 millones de pesos al año (estimado en 2018) para personal y equipo de búsqueda de los desaparecidos, lo cual representa $0.00202 \%$ del pib de ese año.

En nuestra revisión de literatura mencionamos que la esperanza de vida de los hombres se ha mantenido constante, mientras que la de las mujeres aumentó 0.6 años. Imaginemos por un momento que la esperanza de vida de los hombres hubiese aumentado igual que la de las mujeres y se hubiera ubicado en 72.6. Dado que mi estimación del valor presente considera tiempo discreto, voy a redondear esta cifra a 73 años. ¿Cuál es el costo de perder este año adicional de esperanza de vida entre los muertos y desaparecidos? La Tabla 9 presenta los resultados. A 12 ańos el costo compuesto sería de 0.01-0.02 puntos porcentuales adicionales de la tasa de crecimiento del pIB. ${ }^{28}$

Tabla 9. Estimación del costo de la pérdida de vidas y esperanza de vida

$\begin{array}{lcc} & \text { Homicidios } & \text { Homicidios + desaparecidos } \\ \text { Costo de las vidas (millones de pesos) } & 136432 & 158777 \\ \text { Costo simple en términos del PIB 2005 } & 1.820 \% & 2.118 \% \\ \text { Costo compuesto simulado tras 12 años } & 2.5 \% & 2.90 \%\end{array}$

Notas: Elaboración propia.

\subsection{Costo en la actividad económica}

Balmori de la Miyar (2016) estima que 30\% del incremento en los homicidios entre 2007 y 2012 se debe a la guerra contra el narco entre los estados tratados. También que, en promedio, estos tienen un PIB per cápita menor en $0.5 \%$. Suponiendo que las poblaciones de los estados con operaciones conjuntas y los estados sin operaciones conjuntas crecen a la misma tasa, esta diferencia en PIB per cápita equivaldría a la diferencia en рів. Durante este período, la tasa de homicidios de los estados con intervenciones fue de 24.18 por cada 100 mil habitantes, ${ }^{28}$ Este costo se estima entre muertos y desaparecidos porque la pérdida de esperanza de vida entre los hombres se debe justamente a la mayor tasa de mortalidad por homicidio de este grupo de población. 
de las cuales ocho se atribuyen a la guerra contra el narco. Por tanto, un cambio de ocho homicidios por cada 100 mil está ligado a una caída de $0.5 \%$ del PIB de los estados con operaciones conjuntas en promedio. El cambio que se vivió al nivel nacional en la tasa de homicidios fue de 10 (Gráfica 1). Extrapolando este resultado al nivel nacional tendríamos que México perdió $0.625 \%$ del PIB por ańo entre 2003 y 2012.

\subsection{Costo de los cambios en capital humano}

La literatura identifica una caída en 0.21 años de educación entre los jóvenes de 14 a 17 años y una disminución de la probabilidad de concluir la educación básica de hasta 15 pp. entre aquellos de 15 a 16 años por un aumento de 15 homicidios por cada 100 mil habitantes (Brown y Velásquez, 2017). Estas estimaciones son las que consideramos más creíbles dentro de la revisión de la literatura, dado que logran controlar por características no observadas de los individuos o tendencias al nivel municipal. ${ }^{29}$ Tomemos como base de nuestro costo la disminución en 15 pp. en la probabilidad de concluir la secundaria entre los jóvenes de 15 a 16 años; esto es, 15 de cada 100 no terminan la secundaria, adicionalmente. El tamańo de este grupo de edad de acuerdo con los datos de la encuesta intercensal 2015 es de aproximadamente 1823065 jóvenes. Entonces, 273460 no terminarán la secundaria por cada 15 homicidios de aumento en la tasa de estos. Al nivel nacional la tasa de homicidios por cada 100 mil se incrementó en 10 homicidios. Por lo tanto, estos estimados sugieren que 182306 jóvenes no concluirían la secundaria dado el incremento en la tasa de homicidios al nivel nacional.

¿Cuál es la pérdida del flujo salarial anual derivada de esta pérdida de capital humano? Si toma mos en cuenta el valor presente de los flujos salariales de la Tabla 7, no terminar la secundaria implicaría tener un valor presente de nivel primaria completa para el grupo de edad de 12 a 17 ańos, en lugar de tener un valor presente de nivel secundaria completa para ese mismo grupo de edad. ${ }^{30}$ Tomando la diferencia entre el valor presente de secundaria completa menos el valor presente de primaria completa para los hombres de 12 a 17 ańos, obtenemos que la diferencia en flujos salariales es de 42743.10 pesos. Multiplicando esto por los

${ }^{29}$ Se puede consultar la revisión de esta literatura en el Apéndice en línea.

${ }^{30}$ Esto suponiendo que, si se hubiera acabado la secundaria, este hubiera sido el máximo nivel de estudios alcanzado. Esto es, la secundaria completa es el nivel educativo contrafactual. 
182306 jóvenes, obtenemos un costo de 7792 millones de pesos, lo cual equivale a 0.1093 del рів de 2005.

En México no se han elaborado estudios sobre los retornos del peso al nacer, ni sobre el efecto de la depresión en los salarios, así que no es posible monetizar estos costos en términos del pib. Tampoco existe investigación sobre el efecto de una mayor aversión al riesgo en el рів о en el crecimiento económico.

\subsection{Costos totales anuales y costo de la impunidad}

La Tabla 10 resume los costos totales anuales en términos del PIB y representa uno de los resultados principales de este artículo. Algunos se duplican entre sí. Por ejemplo, el costo en crecimiento puede reflejar, entre otras cosas, la pérdida de flujos salariales por la pérdida de vidas o la caída en la escolaridad. Sin embargo, estos no reflejan el costo de largo plazo de tener un menor peso al nacer, el de la depresión, o el de las vidas que no nacieron por la muerte de tantas personas. Tampoco podemos contabilizar todos los costos psíquicos que se derivan de la pérdida de un ser querido, o del desconocimiento de su paradero, ni el verdadero costo de la pérdida de vidas más allá de los flujos salariales potenciales. Tampoco tenemos un estimado del costo del tiempo que dedican las familias a buscar a sus desaparecidos, ni se han considerado los costos materiales relacionados con los homicidios, ya que la estimación que elabora el INEGI se refiere a todas las pérdidas materiales del crimen y no solo de los homicidios. Así que no podemos asegurar que el costo que presentamos esté sobrestimado, y muy posiblemente estemos subestimando el costo total.

De acuerdo con la estimación de Azfar (2005), cambiar el nivel de efectividad del gobierno de México a niveles de Costa Rica disminuiría la tasa de homicidios por cada $100 \mathrm{mil} \mathrm{habitantes} \mathrm{a} \mathrm{la} \mathrm{mitad.} \mathrm{Así} \mathrm{que} \mathrm{tomaremos} \mathrm{esta} \mathrm{estimación} \mathrm{como}$ base para estimar el costo de la impunidad en México, donde la impunidad está medida como instituciones menos efectivas. Recordemos que otras mediciones del costo de la baja calidad institucional de México apuntaban a cifras mayores al $50 \%$, así que esta es una aproximación conservadora del costo de la impunidad. 
Tabla 10. Costos totales anuales en términos del PIB

\begin{tabular}{|c|c|c|}
\hline & $\begin{array}{c}\text { Costo total } \\
(\%)\end{array}$ & $\begin{array}{c}\text { Costo de la impunidad } \\
(50 \% \text { del costo total })^{\mathrm{a}} \\
(\%)\end{array}$ \\
\hline Costo de los homicidios (flujo salarial) & 0.1507 & 0.075 \\
\hline Costo de los desaparecidos (flujo salarial) & 0.0247 & 0.012 \\
\hline Costo de la búsqueda de desaparecidos & 0.00202 & 0.001 \\
\hline Costo de la esperanza de vida (flujo salarial) & 0.0012 & 0.001 \\
\hline $\begin{array}{l}\text { Costo en la actividad económica por un cambio de } 10 \\
\text { por cada } 100 \text { mil hab. en la tasa de homicidios }\end{array}$ & 0.625 & 0.313 \\
\hline $\begin{array}{l}\text { Costo en crecimiento económico por un cambio de } 10 \\
\text { por cada } 100 \text { mil hab. en la tasa de homicidios }{ }^{c}\end{array}$ & 0.25 & 0.125 \\
\hline $\begin{array}{l}\text { Costo de la pérdida de jóvenes que completan la } \\
\text { secundaria }^{\mathrm{d}}\end{array}$ & 0.1039 & 0.052 \\
\hline \multirow[t]{2}{*}{ Costo total } & 1.16 & 0.579 \\
\hline & & $\begin{array}{l}422390 \text { millones } \\
\text { de pesos }\end{array}$ \\
\hline
\end{tabular}

${ }^{a}$ De acuerdo con la estimación de Azfar (2005), cambiar el nivel de efectividad del gobierno de México a niveles de Costa Rica disminuiría la tasa de homicidios por cada 100 mil habitantes a la mitad.

${ }^{\text {b }}$ Estimado a partir de Balmori de la Miyar (2016).

' Enamorado et al. (2014) estimaron una disminución del piB de 0.2 puntos porcentuales por cada ocho homicidios por 100 mil habitantes. El aumento al nivel nacional fue de 10 homicidios por 100 mil habitantes.

d Estimado a partir de Brown y Velásquez (2017).

La Tabla 10 refleja que la impunidad nos cuesta $0.579 \%$ del рів cada año o 422390 millones de pesos. ${ }^{31}$ Finalmente, hacemos un ejercicio similar para saber cuánto nos costará la impunidad a través del tiempo. La Gráfica 4 presenta la trayectoria de crecimiento del рів. Para 2030, el Pıв sería 3.068\% menor que si tuviéramos la calidad institucional de Costa Rica; mientras que para 2050 la brecha se abriría hasta el 13\% del PIв contrafactual. En términos monetarios, la brecha en 2030 ascendería a \$1 841360 millones de pesos, mientras que en 2050 esta sería de $\$ 8740240$ millones de pesos. Este es el costo de la mala efectividad del gobierno mexicano en el mediano plazo.

${ }^{31}$ Esto es tomando en cuenta que el PIB en 2018 (a precios de 2013) ascendió a 74 103523 millones de pesos de acuerdo con el INEGI. https://docs.google.com/ viewer?url=https \%3A\%2F\%2Fwww.inegi.org.mx\%2Fcontenidos\%2Ftemas \%2Feconomia\%2Fpib\%2Fpibt\%2Ftabulados\%2Fori\%2FPIBT_2.xlsx 


\section{Gráfica 4. Comparativo de la trayectoria de crecimiento del PIB con impunidad al nivel México y contrafactual al nivel Costa Rica}

EFECTO EN EL CRECIMIENTO DEL PIB

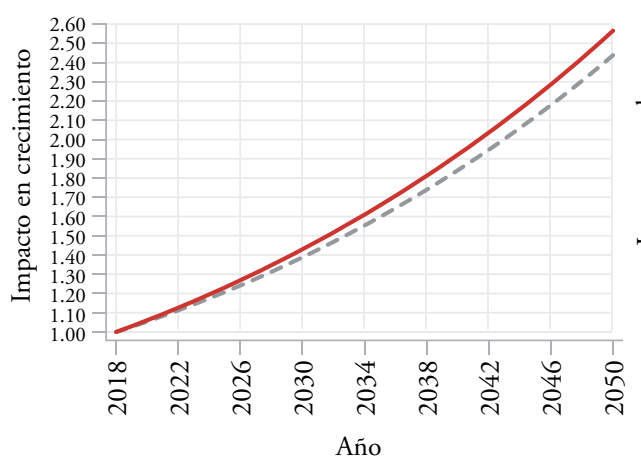

— PIB Contrafactual

- - PIB con costo impunidad
EFECTO EN EL PIB (PESOS DE 2OI3)

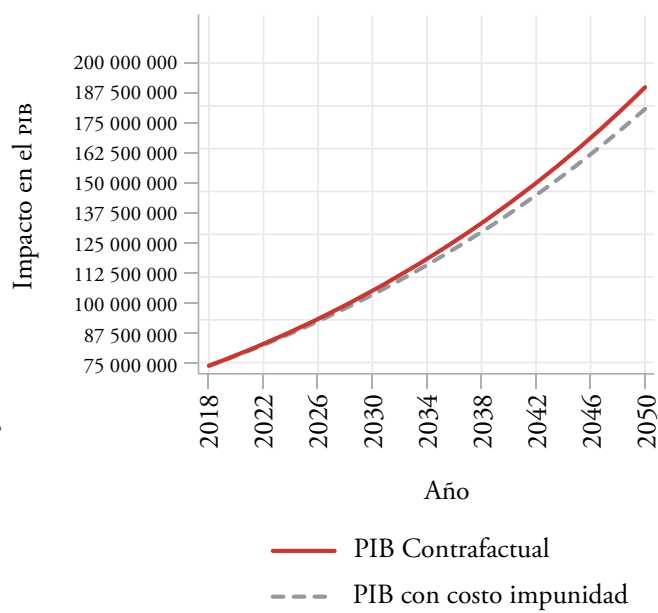

Fuente: Elaboración propia con base en una simulación del PIB y su crecimiento. El pIB se encuentra expresado en pesos de 2013 .

A falta de resultados más confiables de la relación entre impunidad y homicidios en México, utilizaremos los resultados de la relación entre impunidad y desaparecidos para estimar únicamente el costo de la impunidad. Ortizy Vázquez (2019) calculan que por cada punto adicional de impunidad en delitos hay 173 desapariciones más en un año. ${ }^{32}$ Estos mismos autores hallan tasas de impunidad en delitos por arriba del $90 \%$ en todo el territorio mexicano. Así, pensemos en tres escenarios contrafactuales. Primero, imaginemos que logramos reducir la tasa de impunidad de la tasa estatal más alta a la más baja. El estado con la mayor tasa de impunidad en delitos en 2016 fue Guerrero, con 99.2\% en los que no se hizo nada. Por su parte, el estado con la menor tasa de impunidad fue Baja California Sur, con $92.6 \%$ en los que no se hizo nada. Esto representa una diferencia de 7\%. Llamemos a este escenario el escenario contrafactual A. Para el siguiente escenario contrafactual, imaginemos que se puede reducir la tasa de impunidad

${ }^{32}$ La impunidad en delitos contempla al universo de estos en los que "no sucedió nada”, que abarca tres posibilidades: 1) ni siquiera se denunció el delito, 2) se denunció el delito, pero no se abrió una investigación, o 3) se abrió una investigación, pero no hubo una sentencia. En los tres casos, el delito quedó impune. 
en delitos en $10 \%$ (escenario contrafactual B). Por último, imaginemos que podemos reducir la impunidad al nivel de Costa Rica. De acuerdo con el Global Impunity Index 2017 de Le Clercq Ortega y Rodríguez Sánchez Lara (2017), ${ }^{33}$ el índice de Costa Rica es 54.57, mientras que el de México es 69.21. Así, en este escenario contrafactual C, la diferencia en la impunidad es de $27 \%$.

Suponiendo que la relación entre impunidad en delitos y desaparecidos se mantiene constante durante los doce ańos que ha durado la guerra contra el narco, y que esta relación se puede extender a homicidios, entonces podemos hacer una predicción del número de homicidios que se pudieron evitar de haber habido menos impunidad. La Tabla 11 presenta esta predicción. Los distintos escenarios apuntan a que la impunidad nos cuesta entre 6773 y 18304 millones de pesos dependiendo de cuál sea el escenario contrafactual.

\section{Tabla 11. Desapariciones que se pudieron evitar bajo distintos escenarios contrafactuales y su costo total (2007-2018)}

\section{Escenario contrafactual \\ Contrafactual A: Baja la impunidad de la mayor a la menor tasa estatal o 6.6 pp. \\ Contrafactual B: Baja la impunidad en $10 \mathrm{pp}$.}

Contrafactual C: Baja la impunidad a la tasa de Costa Rica (27\% o alrededor de 26 pp.)

\section{Desapariciones prevenidas en los 12 años de la guerra contra el narco}

13702

$37 \%$ de los desaparecidos

20760

$56 \%$ de los desaparecidos

53976

Más del 100\% de los desaparecidos
Costo de la impunidad en términos del PIB y en pesos $0.00914 \%$ del рів 6773 millones de pesos $0.0138 \%$ del pIB

10226 millones de pesos $0.0247 \%$ del pIB 18304 millones de pesos

Para el cálculo de estas desapariciones prevenidas se utiliza el coeficiente estimado por Ortiz y Vázquez (2019), quienes encuentran que por cada punto porcentual adicional de impunidad en delitos hay 173 desapariciones adicionales en un año. Para el cálculo del porcentaje de desaparecidos, se toman como base los 37 mil desaparecidos en los doce ańos de guerra contra el narco. Para estimar el costo de la impunidad en términos del pIB usamos la estimación en flujo de salarios que presentamos en la Tabla 10. Para el cálculo en pesos se usó el PIB de 2018 (a precios de 2013) como base.

${ }^{33}$ El índice considera tres dimensiones: estructural, funcional y derechos humanos. Dentro de las primeras dos, el índice toma en cuenta, además, dos ejes concernientes al sistema de seguridad y al sistema de justicia. La dimensión estructural se refiere a la estructura física y humana: número de policías, jueces, prisiones y personal de las prisiones. La dimensión funcional se refiere al proceso de captura y al proceso judicial de los presuntos delincuentes. Finalmente, los derechos humanos se refieren a la protección de la integridad física de los individuos. 


\section{Conclusiones}

En los últimos doce años México experimentó un marcado incremento en la violencia criminal. Mucha de esta violencia ha estado acompañada por altos niveles de impunidad que han erosionado aún más la confianza de los mexicanos en sus instituciones. El objetivo de este documento es hacer una estimación educada de los costos económicos de la impunidad, y dado que esta abarca un gran número de conductas criminales, en el análisis los acotamos a aquellos relacionados con homicidios, desapariciones y desplazamientos forzados durante la guerra contra el narco. Existen muchos otros crímenes, como los de género, la trata de personas, los secuestros, las extorsiones y otros que también se catapultaron en el período de análisis, pero la literatura no ha tenido el suficiente alcance para cubrirlos.

El análisis del costo de la impunidad se llevó a cabo en tres etapas. Uno muy amplio de la literatura sobre los costos de la violencia criminal desde que inició la guerra contra el narco en México, así como una revisión de la literatura sobre la relación entre calidad institucional, impunidad y legitimidad de las instituciones en homicidios. En una segunda etapa, se estimaron los costos económicos de las pérdidas de vidas mediante una imputación del flujo salarial no realizado de las víctimas, de acuerdo con su grupo de edad, nivel educativo y género. Finalmente, a partir de la literatura y estas imputaciones del valor de las vidas perdidas y las desapariciones se elaboró una estimación del costo económico de la impunidad en México.

A partir de las imputaciones del flujo de salarios perdidos debido al menor logro educativo, la menor esperanza de vida de los hombres y la pérdida de vidas, y de una simulación de las consecuencias en el mediano plazo, estimamos que el costo de que México tenga una impunidad en delitos mayor a la de Costa Rica ha sido de 18304 millones, solamente debido a las desapariciones reportadas hasta noviembre de 2018. Por su parte, tener una peor calidad institucional que Costa Rica nos cuesta cada año 422390 millones de pesos (0.579\% del PIB). Para 2030, si no se perpetra ni un asesinato más, habremos pedido $\$ 1.8$ billones de pesos en comparación con una senda de crecimiento donde no hay asesinatos ni desaparecidos. Finalmente, hacia 2050 el costo ascendería a $\$ 8.7$ billones de pesos (13\% menos PIB que en un México sin muertos ni desaparecidos por el narco). Este es el costo de la falta de efectividad de nuestro gobierno.

En diversas partes del documento hemos advertido sobre las limitaciones de esta estimación, la cual muy probablemente represente una subestimación del verdadero costo de la impunidad en México. Primero, el estudio necesariamente se encuentra acotado al impacto económico de dos crímenes: desapariciones y homicidios. En la literatura 
no hallamos estimaciones consistentes sobre el impacto del crimen organizado en los desplazamientos forzados y, por ello, nos limitamos a desapariciones y homicidios. Así, nuestra estimación ignora el efecto de otras actividades criminales tanto del crimen organizado (secuestros, trata de personas, extorsiones, etcétera) como del crimen común (robos y lesiones), ni tampoco la violencia de género (violencia doméstica, violaciones y vejaciones varias hacia grupos identificados por su género) o la corrupción de los servidores públicos. Todos estos también gozan de una marcada impunidad.

Segundo, la imputación del costo de los asesinados y los desaparecidos se elaboró únicamente con base en la pérdida de salarios del fallecido o desaparecido (suponiendo que este último no trabaja por una remuneración). Esta es una forma muy limitada de valuar las aportaciones de una persona a una sociedad y a su familia. No se contabiliza el costo psíquico para los deudos o las familias que se mantienen a la espera de rencontrarse con su pariente. Más allá de este costo psíquico que puede ser muy subjetivo y no medible en términos económicos, tampoco contamos con una estimación total del costo de perder a alguien: gastos de búsqueda de los familiares o funerarios, en abogados y en la burocracia judicial a la espera de que se haga justicia. En el caso de las mujeres, el costo salarial no refleja el valor económico de su producción dentro del hogar, en el que ellas dominan y del cual también es difícil hacer una medición.

Tercero, dada la falta de análisis económicos, no podemos monetizar los costos de tener una aversión al riesgo más alta, los costos económicos del bajo peso al nacer, los costos de todas las vidas que no nacieron por los homicidios y desapariciones de personas en edad reproductiva, los costos en degradación ambiental por la siembra de amapola o marihuana, o la pérdida de bienestar subjetivo de las personas. No tenemos información para cuantificar todos ellos.

Finalmente, algunos de los costos que listamos podrían estar cuantificados doblemente. Este es el caso de la imputación en pérdida salarial, PIв y crecimiento del pIB. Dado que los salarios son un componente del PIB, los salarios perdidos durante el período 2007-2014 podrían formar parte de las estimaciones presentadas en la literatura. Este no es el caso para el efecto de mediano plazo (a 2030 o 2050), ya que esos salarios son proyectados al futuro. Sin embargo, esta doble contabilización difícilmente rebasará lo que no contabilizamos en los tres puntos citados. Por ello, decimos que muy probablemente el costo que presentamos en este documento se trata de una subestimación del costo total. A pesar de ello, el costo estimado anual hasta 2018 casi equivale a la suma del presupuesto de la Secretaría de Educación Pública y la Secretaría de Salud en el Presupuesto de Egresos de la Federación de 2019. Necesitamos empezar a atacar la impunidad. 


\section{Referencias}

Abadie, A. y Gardeazabal, J. (2003). The Economic Costs of Conflict: A Case Study of the Basque Country. American Economic Review, 93(1). 11332. https://doi.org/10.1257/000282803321455188

Arceo-Gómez, E. O. (2013). Drug-Related Violence and Forced Migration from Mexico to the United States. North American Integration: An Institutional Void in Migration, Security and Development. https://doi. org/10.4324/9780203551264

Atuesta, L. H. y Paredes, D. (2016). Do Mexicans Flee from Violence? The Effects of Drug-Related Violence on Migration Decisions in Mexico. Journal of Ethnic and Migration Studies, 42(3), 480-502. https://doi. org/10.1080/1369183X.2015.1079122

Azfar, O. (2005). Government Effectiveness and Homicides. SSRN Electronic Journal. https://doi.org/10.2139/ssrn.720281

Balmori de la Miyar, J. R. (2016). The Economic Consequences of the Mexican Drug War. Peace Economics, Peace Science and Public Policy, 22(3), 213-46. https://doi.org/10.1515/peps-2016-0014

Basu, S. y Pearlman, S. (2017). Violence and Migration: Evidence from Mexico's Drug War. IZA Journal of Development and Migration, 7(1), 18. https://doi.org/10.1186/s40176-017-0102-6

Becker, G. S. (1968). Crime and Punishment: An Economic Approach. Journal of Political Economy, 76(2), 169-217. https://doi.org/10.1086/259394

Brown, R. y Velásquez, A. (julio de 2017). The Effect of Violent Crime on the Human Capital Accumulation of Young Adults. Journal of Development Economics, 127, 1-12. https://doi.org/10.1016/J.JDEVECO.2017.02.004

Calderón, G., Robles, G., Díaz-Cayeros, A. y Magaloni, B. (2015). The Beheading of Criminal Organizations and the Dynamics of Violence in Mexico. David Shirk, D. y Wallman, J (Eds.). Journal of Conflict Resolution, 59(8), 1455-1485. https://doi.org/10.1177/0022002715587053

Campos-Vazquez, R. (2013). Efectos de los ingresos no reportados en el nivel y tendencia de la pobreza laboral en México. Ensayos Revista de Economía, XXXII(2), 23-54.https://econpapers.repec.org/article/erejournl/v_3axxxii_3ay_3a2013_3ai_3a2_3ap_3a23-54.htm 
Canudas-Romo, V., García-Guerrero, V. M. y Echarri-Cánovas, C. J. (2015). The Stagnation of the Mexican Male Life Expectancy in the First Decade of the 21 st Century: The Impact of Homicides and Diabetes Mellitus. Journal of Epidemiology and Community Health, 69(1), 28-34. https:// doi.org/10.1136/jech-2014-204237

Canudas-Romo, V., Aburto, J. M., García-Guerrero, V. M. y Beltrán-Sánchez, H. (2017). Mexico's Epidemic of Violence and Its Public Health Significance on Average Length of Life. Journal of Epidemiology and Community Health, 71(2), 188-93. https://doi.org/10.1136/jech-2015-207015

Castillo, J. C., Mejía, D. y Restrepo, P. (diciembre de 2018). Scarcity without Leviathan: The Violent Effects of Cocaine Supply Shortages in the Mexican Drug War. The Review of Economics and Statistics, 2, 269-286. https://doi.org/10.1162/rest_a_00801

Clercq Ortega, J. A. Le y Rodríguez Sánchez Lara, G. (2017). GII-2017 Global Impunity Index. www.udlap.mx/cesij

Dell, M. (2015). Trafficking Networks and the Mexican Drug War. American Economic Review, 105(6), 1738-1779. https://doi.org/10.1257/ aer.20121637

Dube, A., Dube, O. y García-Ponce, O. (2013). Cross-Border Spillover: U. S. Gun Laws and Violence in Mexico. American Political Science Review, 107(03), 397-417. https://doi.org/10.1017/S0003055413000178

Dube, O., García-Ponce, O. y Thom, K. (2016). From Maize to Haze: Agricultural Shocks and the Growth of the Mexican Drug Sector. Journal of the European Economic Association, 14(5), 1181-1224. https://doi. org/10.1111/jeea.12172

Enamorado, T., López-Calva, L. F. y Rodríguez-Castelán, C. (2014). Crime and Growth Convergence: Evidence from Mexico. Economics Letters, 125. https://doi.org/10.1016/j.econlet.2014.07.033

Escalante, F. (2011). Homicidios 2008-2009 La Muerte Tiene Permiso. Nexos. https://www.nexos.com.mx/?p=14089

Guerrero-Gutiérrez, E. (2011). Security, Drugsy Violence in Mexico: A Survey. www.lantiaconsultores.com.

Heckman, J. J. (1979). Sample Selection Bias as a Specification Error. Econometrica, 47(1), 153-61.

Hoyos, R. De, Gutiérrez Fierros, C. y Vargas M, J. V. (2016). Idle Youth in Mexico: Trapped between the War on Drugs and Economic Crisis. Policy Research Working Papers, 7558. https://doi.org/10.1596/18139450-7558 
Huebert, E. T. y Brown, D. S. (2019). Due Process and Homicide: A Cross-National Analysis. Political Research Quarterly, 72(1), 190-204. https:// doi.org/10.1177/1065912918785059

INEgI (Instituto Nacional de Estadística y Geografía). (2018). Encuesta Nacional de Victimización y Percepción Sobre Seguridad Pública (ENVIPE) 2018. http://www.beta.inegi.org.mx/proyectos/enchogares/regulares/ envipe $/ 2018$

Merino, José. (2011). Los Operativos conjuntos y la tasa de homicidios: una medición. Nexos. 2011. https://www.nexos.com.mx/?p=14319

Merino, J., Zarkin, J. y Fierro, E. (2013). Marcado para morir. Nexos, 2013. https://www.nexos.com.mx/?p=15375

Mustard, D. B. (2010). How Do Labor Markets Affect Crime? New Evidence on an Old Puzzle. Discussion Paper, 4856. https://docs.iza.org/ dp4856.pdf

Nivette, A. E. y Eisner, M. (2013). Do Legitimate Polities Have Fewer Homicides? A Cross-National Analysis. Homicide Studies, 17(1), 3-26. https://doi.org/10.1177/1088767912452131

Ortiz, H. y Vázquez, D. (2019). Impunidad y Violaciones a Los Derechos Humanos. Manuscrito.

Pinotti, P. (2015). The Economic Costs of Organised Crime: Evidence from Southern Italy. The Economic Journal, 125(586), F203-32. https://doi. org/10.1111/ecoj.12235

Robles, G., Calderón, G. y Magaloni, B. (2015). The Economic Consequences of Drug Trafficking Violence in Mexico. http://www.antoniocasella.eu/ nume/Robles_2015.pdf

Secretariado Ejecutivo del Sistema Nacional de Seguridad Pública. (2018). Datos abiertos de Incidencia Delictiva [base de datos].

Shirk, D. y Wallman, J. (2015). Understanding Mexico's Drug Violence. Shirk, D. y Wallman, J. (Eds.). Journal of Conflict Resolution, 59(8), 1348-1376. https://doi.org/10.1177/0022002715587049

Sistema Nacional de Información en Salud. (2018). Datos abiertos [base de datos].

Velásquez, A. (2019). The Economic Burden of Crime: Evidence from Mexico. Journal of Human Resources. https://doi.org/10.3368/jhr.55.4.07168072R2

World Justice Project. (2016). Rule of Law Index ${ }^{\circledR}$ 2016. https://worldjusticeproject.org/sites/default/files/documents/RoLI_Final-Digital_0.pdf 